\section{Total protein concentration and T-cell suppression activity of aqueous humour before and after penetrating keratoplasty}

J-S Mo', P Maier², D Böhringer², H Reinshagen ${ }^{3}$, R Sundmacher ${ }^{2}$ and $T$ Reinhard ${ }^{2}$

\begin{abstract}
Purpose We wished to determine whether immune privilege parameters assayed in aqueous humour $(\mathrm{AqH})$ are relevant to the fate of penetrating keratoplasty (PK) in humans. Methods $\mathrm{AqH}$ was collected in 28 patients before PK (prospective cohort), in 6 patients with no history of graft rejection undergoing cataract surgery after PK (acceptors), in another 6 patients undergoing treatment of an acute endothelial immune reaction (rejectors), and in 65 controls undergoing uncomplicated cataract extraction. $\mathrm{AqH}$ was tested for total protein concentration and the ability to suppress T-cell activation.

Results $\mathrm{AqH}$ protein concentrations of acceptors and rejectors post-PK were elevated $(2.7 \pm 0.8$ and $2.7 \pm 0.7 \mathrm{mg} / \mathrm{ml}$, respectively) compared with pre-PK AqH level and cataract controls $(1.0 \pm 0.1 \mathrm{mg} / \mathrm{ml}, P=0.01)$. All $\mathrm{AqH}$ samples suppressed T-cell activation, irrespective of source and timing of $\mathrm{AqH}$ removal.

Conclusion Assays of immune privilege markers in AqH suggest that PK surgery may result in a sustained loss of integrity of the blood-aqueous barrier. Although trends were evident, values of immune privilege markers determined pre- and post-PK were not statistically significantly different between the study groups. However, further prospective studies determining additional immune privilege markers have to be conducted in order to find out whether these markers might serve as predictive parameters for immune reactions following $\mathrm{PK}$.
\end{abstract}

Eye (2012) 26, 153-158; doi:10.1038/eye.2011.290; published online 18 November 2011
Keywords: keratoplasty; aqueous humour; immune privilege; blood-aqueous barrier

Introduction

At 5 years after penetrating normal-risk keratoplasty (PK), up to $95 \%$ of the grafts are clear. ${ }^{1}$ Nevertheless, most individuals are likely to be forced to undergo at least a second keratoplasty in their lifetime, as clear graft survival might ultimately be limited by late endothelial failure due to chronic endothelial cell loss: although inter-individual variability is high, $\sim 17 \%$ of central endothelial cell density is lost annually, even in the absence of any clinically evident endothelial immune reaction or any other known damaging factor to the corneal endothelium. ${ }^{2,3}$ Individual extrapolation ${ }^{4}$ implies a life span that might be potentially limited to only around 20 years in most cases, as central endothelial cell density values $<\sim 400$ cells per $\mathrm{mm}^{2}$ are incompatible with clear graft survival. ${ }^{5}$ Although some influencing factors on the individual severity of chronic endothelial cell loss have been established, ${ }^{2}$ the main causative mechanisms remain elusive. A clinically invisible immune reaction directed against endothelial cells is a promising candidate, but immunological involvement has not yet been proven. ${ }^{6}$

Additionally, 23\% of penetrating normal-risk keratoplasties suffer from at least one clinically evident endothelial immune reaction within the first 5 years. ${ }^{1}$ These acute graft reactions further reduce central endothelial density. ${ }^{7}$ Even if endothelial immune reactions are reversible because of intense and early treatment, ${ }^{8}$ the life
${ }^{1}$ Department of Ophthalmology, University of Louisville School of Medicine, Louisville, KY, USA

${ }^{2}$ University Eye Hospital,Freiburg, Germany

${ }^{3}$ Eye Hospital Pallas, Olten, Switzerland

Correspondence: P Maier, University Eye Hospital, Killianstr. 5, 79117 Freiburg, Germany

Tel: + 49761270 40010;

Fax: + 4976127040630 .

E-mail: philip.maier@ uniklinik-freiburg.de

Received: 17 February 2011 Accepted in revised form: 24 September 2011 Published online: 18 November 2011 
the overall functional integrity of the immunosuppressive microenvironment that helps to confer immune privilege on the anterior chamber and indirectly on the corneal allograft.

pave the way for secondary and tertiary prevention.

Studies carried out in experimental animals have shown that deterioration of ocular immune privilege may contribute to corneal allograft rejection and/or severe chronic endothelial cell loss. As there are markers of immune privilege integrity that can be assessed in aqueous humour $(\mathrm{AqH}),{ }^{9,10}$ a study of these immune privilege integrity markers before and after PK seems warranted.

Transforming growth factor (TGF)- $\beta 2$, for example, is one of the most important factors in $\mathrm{AqH}$ to maintain the immunosuppressive climate in the anterior chamber that has a role in immune privilege of the eye. ${ }^{11}$ We found that active $^{12}$ but not total ${ }^{13}$ TGF- $\beta 2$ is decreased in the AqH of patients actively suffering from an endothelial immune reaction. Furthermore, TGF- $\beta 2$ is statistically significantly increased in the $\mathrm{AqH}$ of patients with keratokonus compared with patients with various other corneal diseases. ${ }^{14}$ This may partially explain the excellent prognosis of patients with keratokonus following PK.

In the present study, two putative immune privilege integrity markers are evaluated:

(1) Total AqH protein concentration: The amount of protein in $\mathrm{AqH}$ is an index marker for the integrity of the blood-aqueous barrier, as this barrier normally prevents random diffusion of high-molecular-weight blood components out of the blood vessels. ${ }^{15,16}$

A defective blood-aqueous barrier, in turn, would facilitate enrichment of $\mathrm{AqH}$ for complement factors, circulating antibodies, ${ }^{17,18}$ or metabolites exerting toxicity towards the corneal endothelium. ${ }^{19}$

(2) Capacity of AqH to suppress in vitro the activation of T cells: The immunosuppressive activity of $\mathrm{AqH}$ on T-cells stimulated in vitro by anti-CD3 screens for
By examining the AqH obtained from patients before PK, at the time of graft rejection (rejectors), and at the time of cataract extraction post-PK (acceptors), we determined whether the abnormality of one or more markers of immune privilege integrity in $\mathrm{AqH}$ correlated with the occurrence of graft rejection, and whether the PK itself alters ocular immune privilege.

\section{Materials and methods}

\section{Study design}

Anterior chamber puncture was performed in 28 patients before PK, who were prospectively followed regarding the occurrence of immune reaction; in 6 patients post-PK, with no history of graft rejection and undergoing cataract surgery (acceptors); and in another 6 patients post-PK, who were undergoing treatment of an acute phase of an endothelial immune reaction (rejectors). Data on patients are given in Table 1. As normal controls, 65 patients undergoing uncomplicated cataract surgery provided normal $\mathrm{AqH}$. AqH samples were assayed for total protein content and capacity to suppress T-cell activation in vitro. Data were collected after obtaining written informed consent in adherence to the Declaration of Helsinki for research involving human subjects. The local Ethics Committees approved the research.

\section{Anterior chamber paracentesis}

Anterior chamber puncture was performed under the operation microscope after administering topical or retrobulbar anaesthesia within $24 \mathrm{~h}$ after referral of the

Table 1 Patients, organ culture and donor data

\begin{tabular}{|c|c|c|c|c|}
\hline & $\begin{array}{c}\text { Group 1: } \\
\text { prospective cohort }\end{array}$ & $\begin{array}{l}\text { Group 2: } \\
\text { acceptors }\end{array}$ & $\begin{array}{l}\text { Group 3: } \\
\text { rejectors }\end{array}$ & P-value \\
\hline$n$ & 28 & 6 & 6 & - \\
\hline Time interval from keratoplasty to puncture (days) & - & $311.5 \pm 71.6$ & $222.8 \pm 29.0$ & $0.28^{\mathrm{a}}$ \\
\hline Percentage with up to two HLA mismatches (A/B/DR) & 72.2 & 16.7 & 50.0 & $0.27^{\mathrm{b}}$ \\
\hline Percentage normal risk keratoplasties & 64.7 & 66.7 & 33.3 & $0.28^{\mathrm{b}}$ \\
\hline Age of patients (years) & $63.8 \pm 4.1$ & $61.7 \pm 3.6$ & $57.0 \pm 8.6$ & $0.63^{\mathrm{a}}$ \\
\hline Age of donors (years) & $67.0 \pm 0.4$ & $69.7 \pm 5.0$ & $58 . \pm 7.8$ & $0.24^{\mathrm{a}}$ \\
\hline Post-mortem time (h) & $19.2 \pm 4.6$ & $14.8 \pm 5.7$ & $21.6 \pm 8.9$ & $0.54^{\mathrm{a}}$ \\
\hline Storage time in organ culture (days) & $17.2 \pm 0.6$ & $18.5 \pm 1.4$ & $16.2 \pm 0.9$ & $0.20^{\mathrm{a}}$ \\
\hline Endothelial cell density after organ culture (cells $/ \mathrm{mm}^{2}$ ) & $2457.7 \pm 61.0$ & $2231.0 \pm 45.5$ & $2381.3 \pm 80.3$ & $0.14^{\mathrm{a}}$ \\
\hline Follow-up (days) & $551.3 \pm 40.7$ & $697.3 \pm 70.5$ & $518.7 \pm 120.6$ & $0.23^{\mathrm{a}}$ \\
\hline
\end{tabular}

Mean \pm SEM statistical tests for comparison of group 2 and group 3 .

${ }^{\mathrm{a} A N O V A .}$

${ }^{\mathrm{b}} \chi^{2}$-test. 
patients to the clinic. All eyes were rinsed with a sterile solution (BSS) before anterior chamber puncture.

A paracentesis lancet was used to penetrate the cornea in an avascular peripheral area over a length of $1 \mathrm{~mm}$.

Contamination from limbal or peripheral corneal vessels was avoided carefully. AqH $(0.05-0.1 \mathrm{ml})$ was collected in conventional tuberculin syringes, transferred to plastic vials, and immediately frozen $\left(-50^{\circ} \mathrm{C}\right)$.

\section{Penetrating keratoplasty}

Only donor corneas that met the EEBA criteria ${ }^{20}$ were used for surgery. All corneas had been held in organ culture for at least 10 days. The data of donors are given in Table 1.

\section{Assessment of rejection-free clear graft survival}

Visits were scheduled 6 weeks, 4 and 12 months postoperatively. Long-term follow-up was scheduled yearly.

Immune reactions were diagnosed when either endothelial precipitates or stromal oedema was present in the graft. In case of graft rejection the anterior chamber was infused with corticosteroids ${ }^{8}$ for therapeutic reasons immediately in those patients. Afterwards all patients suffering from the immune reactions were treated with corticosteroid eye drops (prednisolone-21-acetate 1\%) every hour, and the dosage was tapered individually until all precipitates were eliminated. Furthermore, a subconjunctival injection with betamethasone-21-acetate was performed. In severe cases, where extensive corneal oedema was present, systemic corticosteroids at a daily oral dose of $1 \mathrm{mg}$ fluocortolone per $\mathrm{kg}$ body mass were administered additionally and tapered within 3 weeks.

\section{Analysis of AqH samples}

\section{Measurement of total protein concentration}

Protein levels in $\mathrm{AqH}$ were analysed using a protein assay kit (BCA; Pierce, Rockford, IL, USA). Bovine serum albumin was used as a standard.

\section{Effect of AqH on T-cell proliferation stimulated in vitro} by anti-CD3mAb

T-cell proliferation was assayed in a miniculture system as described previously. ${ }^{21}$ Spleens were removed from naive BALB/c mice and pressed through nylon mesh to produce single-cell suspensions. Red blood cells were lysed with Tri- $\mathrm{NH}_{4} \mathrm{Cl}$. T cells were subsequently purified by passing through a T-cell enrichment column (R\&D Systems, Minneapolis, MN, USA). The enriched T cells were suspended in serum-free medium composed of RPMI 1640 medium, $10 \mathrm{mM}$ HEPES, $0.1 \mathrm{mM}$ nonessential amino acids, $1 \mathrm{mM}$ sodium pyruvate, $100 \mathrm{U} / \mathrm{ml}$ penicillin, $100 \mu \mathrm{g} / \mathrm{ml}$ streptomycin (all from BioWhittaker, Lancaster, MA, USA), and $100 \mathrm{mM}$ 2-ME (Sigma Chemicals, St Louis, MO, USA), and supplemented with $0.1 \%$ bovine serum albumin (Sigma, Chemicals), insulin, transferrin, and selenium (ITS +) culture supplement $(1 \mu \mathrm{g} / \mathrm{ml}$ iron-free transferrin, $10 \mathrm{ng} / \mathrm{ml}$ linoleic acid, $0.3 \mathrm{ng} / \mathrm{ml} \mathrm{Na}_{2} \mathrm{Se}$, and $0.2 \mu \mathrm{g} / \mathrm{ml}$ $\mathrm{Fe}\left[\mathrm{NO}_{3}\right]_{3}$ (Collaborative Biomedical Products, Bedford, MA, USA). A 96-well V-shaped bottom plate (Corning, NY, USA) was used in the assay. Twenty-five thousand $(2.5 \times 104)$ enriched $\mathrm{T}$ cells in $10 \mu \mathrm{l}$ serum-free medium and $5 \mu \mathrm{l}$ of AqH or PBS were added to each well and cultured for $1 \mathrm{~h}$. Then $10 \mu \mathrm{l}$ hamster anti-mouse CD3e IgG (2C11, $2.5 \mu \mathrm{g} / \mathrm{ml}$; PharMingen, San Diego, CA, USA) in $10 \mu \mathrm{l}$ serum-free medium (or $10 \mu \mathrm{l}$ serum-free medium alone, as negative control) was added to the well. The cells were pulsed with $2.5 \mu \mathrm{l} 20 \mathrm{Ci} / \mathrm{ml}[3 \mathrm{H}]$ thymidine for the final $8 \mathrm{~h}$ of the $48-\mathrm{h}$ incubation $\left(37^{\circ} \mathrm{C}, 5 \% \mathrm{CO}_{2}-95 \%\right.$ humidified air mixture), and recovered using a cell harvester (model 96, Tomtec, Orange, CT, USA). Thymidine $[3 \mathrm{H}]$ incorporation was measured in counts per minute, using a liquid scintillation counter (Betaplate 1205; Wallac, Gaithersburg, MD, USA). Each AqH sample was distributed to three wells of the culture and average of the counting from the three wells was regarded as the final reading of the sample.

\section{Statistical analysis}

Statistical analysis was performed in order to detect differences between groups in the two individual integrity markers defined above. Total protein concentration and ability of $\mathrm{AqH}$ samples to suppress in vitro stimulation of $\mathrm{T}$ cells were compared between groups by means of Student's $t$-test.

\section{Results}

\section{Assay of protein content of AqH samples}

$\mathrm{AqH}$ collected from control patients undergoing cataract extraction showed a mean total protein concentration of $1.0 \pm 0.1 \mathrm{SEM} \mathrm{mg} / \mathrm{ml}(n=65$, Figure 1$)$. Similarly, the mean protein concentration in $\mathrm{AqH}$ from patients before PK was also $1.0 \pm 0.3 \mathrm{SEM} \mathrm{mg/ml} \mathrm{(} n=24$, Figure 1$)$. By contrast, $\mathrm{AqH}$ samples obtained from eyes with rejected cornea grafts $(n=6)$ and from eyes with accepted cornea grafts $(n=6)$ showed elevated levels of total protein, each with a mean value of $\sim 2.7 \mathrm{mg} / \mathrm{ml}$ (Figure 1). Although there is no statistically significant difference between the protein levels of $\mathrm{AqH}$ from eyes with rejected grafts and those from eyes with accepted grafts, the protein levels in both groups were significantly higher than the protein levels in cataract control $\mathrm{AqH}$ and pre-PK AqH (Figure 1). 


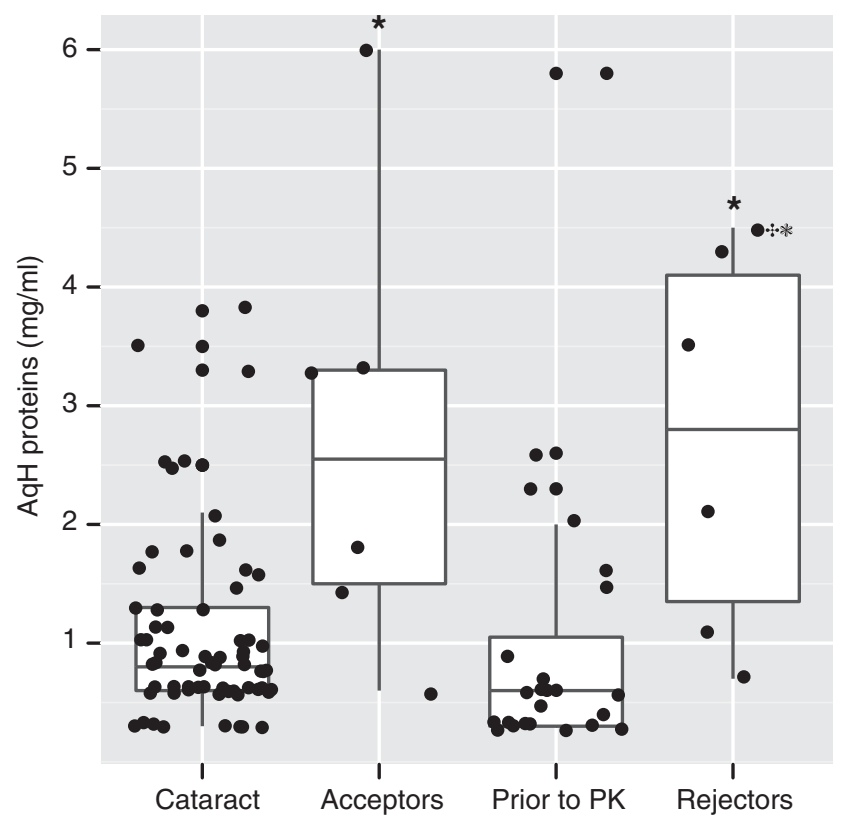

Figure 1 Box plot of total protein concentrations in $\mathrm{AqH}$. AqH samples were obtained from cataract controls $(n=65)$, from patients at the time of subsequent cataract surgery (acceptors, $n=6)$, from patients before PK $(n=28)$, and during rejection (rejectors, $n=6$ ). Values in the box-plot diagram are given as median, $25 / 75 \%$ percentiles (boxes), $10 / 90 \%$ percentiles (bars) and individual values (dots) of the total protein concentration. ${ }^{*}$ indicates mean values statistically significantly greater than cataract controls, $P<0.05$.

These results indicate that breakdown of the blood-ocular barrier (as revealed by elevated protein levels in $\mathrm{AqH}$ ) is a typical sequel of PK, and that this condition persists for an extended period of time post surgery, irrespective of whether the graft is rejected or accepted.

\section{Assay of effects of AqH on T-cell proliferation}

$\mathrm{AqH}$ samples were also tested for their capacity to suppress proliferation of murine T-cells stimulated in vitro with the mitogenic antibody anti-CD3. As the results displayed in Figure 2 reveal, $\mathrm{AqH}$ from cataract control eyes suppressed T-cell proliferation profoundly (37\% of positive control). AqH from pre-PK donor eyes, as well as from rejector and acceptor eyes similarly suppressed T-cell activation (all $<37 \%$ of positive control). There is no statistically significant difference among these four groups. These findings indicate that the capacity of $\mathrm{AqH}$ to suppress T-cell activation in vitro is not altered by the disease processes creating the need for PK or by the PK surgical procedure itself, nor by the ultimate fate of the graft.

\section{Discussion}

It is anticipated that ocular surgeries such as PK cause a breakdown in the blood-ocular barrier. In fact, short-term disintegration of the blood-aqueous barrier

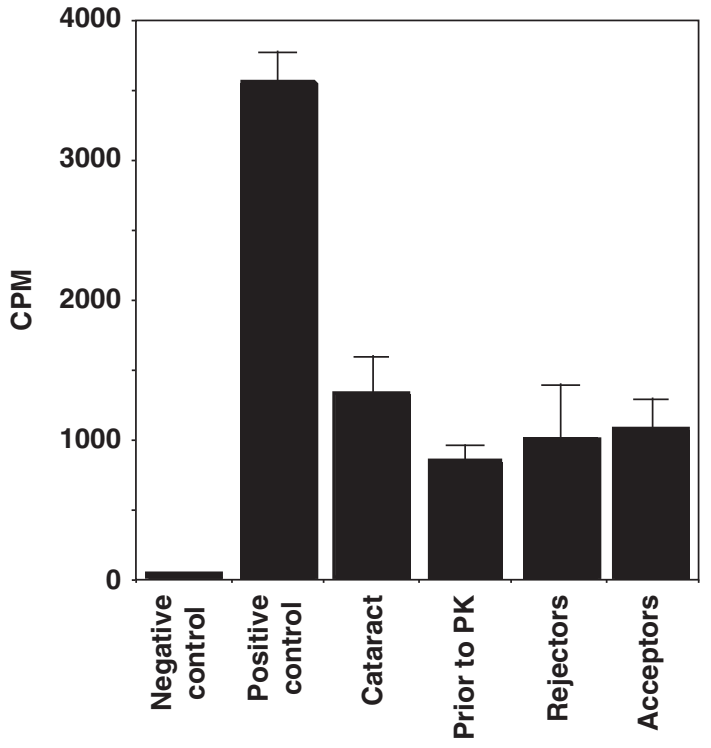

Figure 2 Effects of $\mathrm{AqH}$ on $\mathrm{T}$-cell proliferation. Murine $\mathrm{T}$ cells $\left(\mathrm{BALB} / \mathrm{c}, 2.5 \times 10^{4}\right)$ were cultured with anti-CD3 antibody (2C11, positive control) or without 2C11 (negative control), or with anti-CD3 antibody plus AqH (5 $\mu \mathrm{l} /$ well) from the different patient groups described in the legend to Figure 1. After $48 \mathrm{~h}$ of incubation and $8 \mathrm{~h}$ of pulse with $\left[{ }^{3} \mathrm{H}\right]$ thymidine, radioisotope incorporation was measured in counts per minute. Values represent mean \pm SEM. No statistically significant differences between the study groups were observed. 
after PK has been observed after $\mathrm{PK}^{22-24}$ by means of laser flare tyndallometry, which provides a non-invasive estimation of the total protein concentration in $\mathrm{AqH} .{ }^{24}$ Massive disruption of the barrier, as diagnosed from increased anterior chamber flare-tyndallometry values, has been associated with an increased risk of developing rejection episodes. ${ }^{24}$ However, our results on total protein content during graft rejection could not confirm this association. Our results rather indicate that a compromised blood-aqueous barrier, based on significantly elevated protein concentrations in $\mathrm{AqH}$, is a persistent feature of eyes following PK, irrespective of whether the grafts are accepted or rejected. Therefore, the finding of increased $\mathrm{AqH}$ protein concentration in only the post-PK specimens indicates that this is a postsurgical and not allospecific effect on account of the more traumatic surgery compared with cataract extraction. Moreover, our findings imply that reestablishment of a blood-aqueous barrier is not readily achieved after PK.

Our finding that $\mathrm{AqH}$ protein concentrations remain abnormally high even after 1 year post-PK is striking because previous studies have reported a return within less than a year to a normal blood-aqueous barrier based on $\mathrm{AqH}$ laser flare values. ${ }^{22-24}$ It is possible that direct measurement of the $\mathrm{AqH}$ concentration of protein may prove to be a more sensitive indicator of the integrity of the blood-aqueous barrier than $\mathrm{AqH}$ laser flare. In contrast to our results, Van Gelderen et al. ${ }^{25}$ found that 5 months following PK, the total protein content in the AqH of patients with accepted grafts was lower compared with patients with graft rejection or herpetic stromal keratitis. Furthermore, we cannot conclude that the observed breakdown of the blood-aqueous

barrier is specifically found following PK as we did not include a second control group (eg, patients following cataract).

It is of further interest that the capacity of $\mathrm{AqH}$ to suppress T-cell activation in vitro is still a characteristic of $\mathrm{AqH}$ from patients who had undergone PK before, as this kind of $\mathrm{AqH}$ contains high levels of proteins that have leaked through a compromised blood-aqueous barrier. Recent studies of AqH removed from the eyes of mice with experimentally induced inflammation in the anterior chamber have yielded a similar result. AqH from the eyes of mice with experimental autoimmune uveitis recovers its capacity to suppress T-cell activation in vitro even while the intraocular inflammation accelerates. ${ }^{26}$ Similarly, AqH from the eyes of mice in which anterior uveitis has been induced with an intravitreal injection of bacterial lipopolysaccharide is profoundly inhibitory of T-cell activation in vitro. ${ }^{21}$ The immunosuppressive factor closely linked with suppression in these uveitic eyes is active TGF- $\beta$. This is in line with previous reports that suggest that high levels of TGF- $\beta$ may be protective for immune reactions after PK. ${ }^{10,12}$ The pan-T-cell suppressor activity measure in this experimental setting does not seem to be an adequate parameter to characterize the status of the immune privilege following PK. However, there are many more factors that influence the immune privilege of the anterior chamber that may be helpful in explaining immune reactions following PK. ${ }^{27}$ Analysing the levels of individual cytokines or cytokine patterns in the $\mathrm{AqH}$ for example might give more specific information on the disturbances of the immune privilege in the anterior chamber. ${ }^{12,13,28-31}$

It was disappointing to learn that total protein content and capacity to suppress T-cell proliferation by $\mathrm{AqH}$ failed to correlate with graft rejection. As studies conducted in mice have already demonstrated, the eye subjected to trauma or an inflammatory insult can call upon multiple, nested strategies to maintain local immunosuppression (suppression of T-cell proliferation). Therefore, any assay of AqH that simply assesses global immunosuppression will fail to distinguish strategies that promote graft acceptance from strategies to avoid graft rejection. Furthermore, the low number of samples in this investigation regarding patients following PK, with only six patients in each group, is another limitation regarding the interpretation of the presented results. We hope that future studies targeting other immunomodulatory factors in $\mathrm{AqH}$ (such as various interleukins, thrombospondin, and alpha-melanocytestimulating hormone) may prove to be helpful in predicting the risk of immune reactions following PK.

\section{Summary}

\section{What was known before}

- Despite the immunological privilege of the anterior ocular segment immune reactions are still the major reason for graft failure following penetrating keratoplasty. However, the mechanisms leading to graft rejection are not fully understood. Until now there are only clinically defined risk factors helping to decide who is at high risk for graft rejection and who is not.

What this study adds

- The analysis of aqueous humour from patients with and without immune reactions following keratoplasty revealed that the blood-aqueous barrier is broken down for more than 1 year after surgery. Furthermore, the capability of aqueous humour to suppress T-cell activation did not change after keratoplasty compared with controls independently of the occurrence of immune reactions. Finally, determination of total protein content and the capability to suppress T-cell activation in aqueous humour could not help to differentiate between patients with and without immune reactions, and so more specific immunological parameters in aqueous humour need to be analysed in the future. 


\section{Conflict of interest}

The authors declare no conflict of interest.

\section{Acknowledgements}

We acknowledge with gratitude the late Professor Wayne Streilein, whose advice and assistance in conceiving this study was invaluable. We thank Jacqueline Doherty for expert laboratory management. This study was supported by NIH grants EY05678 and 7R03EY014578.

\section{References}

1 Bohringer D, Reinhard T, Sundmacher R. Systematic EDP-supported acquisition of follow-up data of keratoplasty patients - report on ten years' experience. Klin Monbl Augenheilkd 2003; 220: 253-256.

2 Bohringer D, Reinhard T, Spelsberg H, Sundmacher R. Influencing factors on chronic endothelial cell loss characterised in a homogeneous group of patients. Br J Ophthalmol 2002; 86: 35-38.

3 Ing JJ, Ing HH, Nelson LR, Hodge DO, Bourne WM. Ten-year postoperative results of penetrating keratoplasty. Ophthalmology 1998; 105: 1855-1865.

4 Bohringer D, Reinhard T, Godehardt E, Sundmacher R. Regression analysis of idiopathic endothelial cell loss after perforating normal risk keratoplasty: basic principles for long-term analysis of endothelial risk factors in a retrospec tive clinical study. Klin Monbl Augenheilkd 2001; 218: 412-417.

5 Armitage WJ, Dick AD, Bourne WM. Predicting endothelial cell loss and long-term corneal graft survival. Invest Ophthalmol Vis Sci 2003; 44: 3326-3331.

6 Reinhard T, Bohringer D, Enczmann J, Kögler G, Wernet P, Böhringer $\mathrm{S}$ et al. HLA class I/II matching and chronic endothelial cell loss in penetrating normal risk keratoplasty. Acta Ophthalmol Scand 2004; 82: 13-18.

7 Musch DC, Schwartz AE, Fitzgerald-Shelton K, Sugar A, Meyer RF. The effect of allograft rejection after penetrating keratoplasty on central endothelial cell density. Am J Ophthalmol 1991; 111: 739-742.

8 Reinhard T, Sundmacher R. Adjunctive intracameral application of corticosteroids in patients with endothelial immune reactions after penetrating keratoplasty: a pilot study. Transpl Int 2002; 15: 81-88.

9 van Gelderen BE, Van Der Lelij A, Peek R, Broersma L, Treffers WF, Ruijter JM et al. Cytokines in aqueous humour and serum before and after corneal transplantation and during rejection. Ophthalmic Res 2000; 32: 157-164.

10 Dekaris I, Gabric N, Mazuran R, Karaman Z, Mravicić I. Profile of cytokines in aqueous humor from corneal graft recipients. Croat Med J 2001; 42: 650-656.

11 Cousins SW, McCabe MM, Danielpour D, Streilein JW. Identification of transforming growth factor-beta as an immunosuppressive factor in aqueous humor. Invest Ophthalmol Vis Sci 1991; 32: 2201-2211.

12 Maier P, Broszinski A, Heizmann U, Reinhard T. Decreased active TGF-beta2 levels in the aqueous humour during immune reactions following penetrating keratoplasty. Eye 2008; 22: 569-575.

13 Reinhard T, Bonig H, Mayweg S, Böhringer D, Göbel U, Sundmacher R. Soluble Fas ligand and transforming growth factor beta2 in the aqueous humor of patients with endothelial immune reactions after penetrating keratoplasty. Arch Ophthalmol 2002; 120: 1630-1635.

14 Maier P, Broszinski A, Heizmann U, Böhringer D, Reinhardau T. Active transforming growth factor-beta2 is increased in the aqueous humor of keratoconus patients. Mol Vis 2007; 13: 1198-1202.

15 Butler JM, Unger WG, Grierson I. Recent experimental studies on the blood-aqueous barrier: the anatomical basis of the response to injury. Eye (Lond) 1988; 2(Suppl): S213-S220.

16 Bill A. The blood-aqueous barrier. Trans Ophthalmol Soc UK 1986; 105: 149-155.

17 Hahn AB, Foulks GN, Enger C, Fink N, Stark WJ, Hopkins KA et al. The association of lymphocytotoxic antibodies with corneal allograft rejection in high risk patients. The Collaborative Corneal Transplantation Studies Research Group. Transplantation 1995; 59: 21-27.

18 Roy R, Boisjoly HM, Wagner E, Langlois A, Bernard PM, Bazin $\mathrm{R}$ et al. Pretransplant and posttransplant antibodies in human corneal transplantation. Transplantation 1992; 54: 463-467.

19 Liu SH, Gottsch JD. Apoptosis induced by a cornealendothelium-derived cytokine. Invest Ophthalmol Vis Sci 1999; 40: 3152-3159.

20 Pels E, Tullo A. Directory of European eye banks, 8th edn. Amsterdam: EEBA 2000.

21 Mo JS, Streilein JW. Immune privilege persists in eyes with extreme inflammation induced by intravitreal LPS. Eur J Immunol 2001; 31: 3806-3815.

22 Kuchle M, Nguyen NX, Naumann GO. Aqueous flare following penetrating keratoplasty and in corneal graft rejection. Arch Ophthalmol 1994; 112: 354-358.

23 Nguyen NX, Langenbucher A, Seitz B, Graupner M, Cursiefen $\mathrm{C}$, Küchle $\mathrm{M}$ et al. Blood-aqueous barrier breakdown after penetrating keratoplasty with simultaneous extracapsular cataract extraction and posterior chamber lens implantation. Graefes Arch Clin Exp Ophthalmol 2001; 239: 114-117.

24 Ma DH, See LC, Chen JJ. Long-term observation of aqueous flare following penetrating keratoplasty. Cornea 2003; 22: 413-419.

25 van Gelderen EB, Van der Lelij A, Volker-Dieben HJ, van der Gaag R, Peek R, Treffers WF. Are cytokine patterns in aqueous humour useful in distinguishing corneal graft rejection from opacification due to herpetic stromal keratitis? Doc Ophthalmol 1999; 99: 171-182.

26 Ohta K, Wiggert B, Yamagami S, Taylor AW, Streilein JW. Analysis of immunomodulatory activities of aqueous humor from eyes of mice with experimental autoimmune uveitis. J Immunol 2000; 164: 1185-1192.

27 Niederkorn JY, Larkin DF. Immune privilege of corneal allografts. Ocul Immunol Inflamm 2010; 18: 162-171.

28 Funding M, Hansen TK, Gjedsted J, Ehlers N. Simultaneous quantification of 17 immune mediators in aqueous humour from patients with corneal rejection. Acta Ophthalmol Scand 2006; 84: 759-765.

29 Flynn TH, Mitchison NA, Ono SJ, Larkin DF. Aqueous humor alloreactive cell phenotypes, cytokines and chemokines in corneal allograft rejection. Am J Transplant 2008; 8: 1537-1543.

30 Maier P, Heizmann U, Böhringer D, Kern Y, Reinhard T. Distinct cytokine pattern in aqueous humor during immune reactions following penetrating keratoplasty. Mol Vis 2010; 16: 53-60.

31 Maier P, Heizmann U, Bohringer D, Kern Y, Reinhard T. Predicting the risk for corneal graft rejection by aqueous humor analysis. Mol Vis 2011; 17: 1016-1023. 